\title{
Analytical Hierarchy Process untuk Menentukan Prioritas Proyek
}

\author{
Dilla Kardila ${ }^{1}$, Indra Ranggadara ${ }^{2}$ \\ Fakultas Ilmu Komputer, Universitas Mercubuana \\ Jl. Raya Meruya Selatan, Kembangan, Jakarta, 11650 \\ e-mail: 141815120113@student.merbuana.ac.id, ${ }^{2}$ indra.ranggadara@mercubuana.ac.id
}

Diterima: 7 April 2020; Direvisi: 30 April 2020; Disetujui: 6 Mei 2020

\begin{abstract}
Abstrak
Laksakusuma Arsitek bergerak dalam bidang jasa arsitektur dan interior. Dalam pelaksanaanya seiring dengan berjalannya waktu jumlah proyek yang ditangani tidak memperhatikan ketersediaan sumber daya yang menjadi faktor utama dalam penentuan prioritas. Prioritas dibutuhkan oleh sebuah organisasi untuk mencapai sebuah tujuan. Diperlukan manajemen prioritas yang baik untuk membantu mengelola proyek sesuai dengan waktu yang telah ditentukan demi mencapai keberhasilan dalam sebuah proyek. Analytical Hierarchy Process (AHP) sebuah metode yang dapat membantu dalam menentukan prioritas yang melibatkan beberapa kriteria dan beberapa alternatif. Dalam penelitian ini, Analytical Hierarchy Process (AHP) digunakan untuk menentukan prioritas proyek, yang didalamnya terdapat beberapa kriteria masalah yang menjadi dasar pertimbangan diantaranya biaya, jadwal, resource, material, dan rancangan. Dengan beberapa alternatif diantaranya konstruksi desain dan renovasi. Hasi yang diperoleh dalam menentukan prioritas proyek ini dengan nilai 0,510 dengan pilihan alternatif konstruksi.
\end{abstract}

Kata kunci: ahp, arsitek, manajemen, monitoring, proyek

\begin{abstract}
Laksakusuma Architect is engaged in architectural and interior services. In its implementation over time the number of projects handled does not pay attention to the availability of resources which is a major factor in determining priorities. Priority is needed by an organization to achieve a goal. Good priority management is needed to help manage the project in accordance with the specified time in order to achieve success in a project. Analytical Hierarchy Process (AHP), a method that can help in determining priorities involving several criteria and alternatives. In this study, the Analytical Hierarchy Process (AHP) is used to determine project priorities, in which there are several criteria for problems that become the basis of consideration including costs, schedules, resources, materials, and designs. With several alternatives including construction design and renovation. The result obtained in determining the priority of this project is 0.510 with alternative construction options.
\end{abstract}

Keywords: ahp, architect, management, monitoring, project

\section{PENDAHULUAN}

Dewasa ini dunia arsitek sangat lekat dengan penggunaan media digital untuk hal mendesain baik sebagai media presentasi maupun media desain. Laksakusuma Arsitek memiliki spesialisasi dalam bidang jasa arsitektur mencakup jasa desain, konstruksi atau rancang bangun 
dan renovasi. Dalam proyek konstruksi, terdapat beberapa hal yang harus diperhatikan untuk perencanaan ataupun pengendalian proyek, diantaranya biaya, mutu dan waktu [1]. Bukanlah suatu yang mudah dalam mengelola proyek dari mulai perencanaan sampai dengan pelaksanaan dari hal biaya, waktu, sumber daya manusia serta mutu yang telah ditentukan jika masih terpisah untuk masing-masing aspek. Untuk mendapatkan hasil analisa perencanaan yang baik seorang proyek manajer harus mampu melakukan analisa terhadap seluruh komponen pekerjaan. Dibutukan suatu sistem yang mampu memberikan solusi alternatif agar suatu proyek dapat tersusun lebih baik dalam pelaksanaannya. Seiring dengan bertambahnya jumlah proyek yang dikerjakan dalam satu waktu, penentuan prioritas proyek menjadi masalah dalam menjalankan strategi bisnis. Sehingga diperlukan sistem yang dapat membantu seorang manajer dalam membuat keputusan dan mempertimbangkan prioritas proyek berdasarkan keinginan dengan memperhatikan kriteria-kriteria yang dimiliki. Tujuan dari sistem pengambilan keputusan untuk membantu seorang manajer dalam mengambil keputusan dalam memperluas kapabilitas mereka, tetapi tidak dijadikan untuk menggantikan penilaian mereka [2]. Dalam pelaksanaannya, agar dapat mendapatkan hasil yang optimal, sistem pengambilan keputusan diharapkan sederhana, pengawasan yang lebih mudah, lengkap, efisien dan mudah dipahami oleh user [3].

Dalam penelitian ini, berdasarkan masalah yang dihadapi metode yang akan digunakan adalah Analytical Hierarchy Process untuk membantu menetapkan prioritas untuk berbagai pilihan menggunakan berbagai kriteria. Berdasarkan penelitian sebelumnya yang dilakukan [4] dengan judul "Analisa Strategi Pemasaran Produk Kosmetik Wardah Dengan Pendekatan SWOTAHP untuk menentukan tingkat kepentingan faktor-faktor yang mempengaruhi strategi pemasaran perusahaan. Selanjutnya penelitian yang dilakukan oleh [5] dengan judul "Sistem Pendukung Keputusan Kelompok Pemilihan Tempat PKL Mahasiswa Dengan Menggunakan Metode AHP dan Borda" yang bertujuan untuk mencari nilai tertinggi dari setiap mahasiswa untuk alternatif perusahaan. Penelitian selanjutnya dilakukan [6] dengan judul "Sistem Pendukung Keputusan Penentuan Prioritas Pemadaman Hotspot Kebakaran Hutan dan Lahan Menggunakan Metode Analytical Hierarchy Process dan Weighted Product" dengan pengujian sistem menentukan ranking hotspot yang menjadi prioritas untuk dipadamkan berdasarkan data masukan luas daerah yang terbakar, jarak dari sumber air, waktu yang ditempuh, jenis tanah, jarak dari jalan, jarak dari posko, arah mata angin, jarak dari pemukiman, jarak dari suaka alam, jarak dari lahan produktif dan kelerangan permukaan.

Proses pengambilan suatu keputusan yang dilakukan adalah memilih alternatif. Analytical Hierarchy Process (AHP) menggunakan metode sebuah hirarki secara fungsional dengan input utama dari persepsi manusia [7]. Berdasarkan permasalahan yang dideskripsikan sebelumnya, dapat diformulasikan menggunakan metode Analytical Hierarchy Process (AHP) untuk menentukan prioritas proyek.

\section{METODE PENELITIAN}

Adapun prinsip dasar yang dilakukan dalam mengambangkan AHP diantaranya susunan gambar hirarki, penilaian pada kriteria dan alternatif, menentukan prioritas dan mengukur konsistensi [8]. Dalam menentukan suatu prioritas serta evaluasi pengujian konsistensi diperlukan pada pilihan yang ditelah dibuat. Dalam pengambilan keputusan tidak dipengaruhi oleh satu faktor tetapi beberapa faktor dan mencakup tingkatan prioritas. [9]. Dalam fungsinya AHP mampu menguraikan masalah yang memiliki beberapa faktor atau beberapa kriteria yang kompleks untuk menjadi suatu hirarki [10]. Dalam AHP terdapat 4 prinsip dasar yang harus dipahami, yaitu [6]:

1. Decomposition, yaitu memecahkan masalah komplek ke dalam bentuk hirarki yang saling berhubungan, hirarki pertama yaitu tujuan, hirarki kedua kriteria dan hirarki ketiga yaitu alternatif seperti pada gambar 1 . 


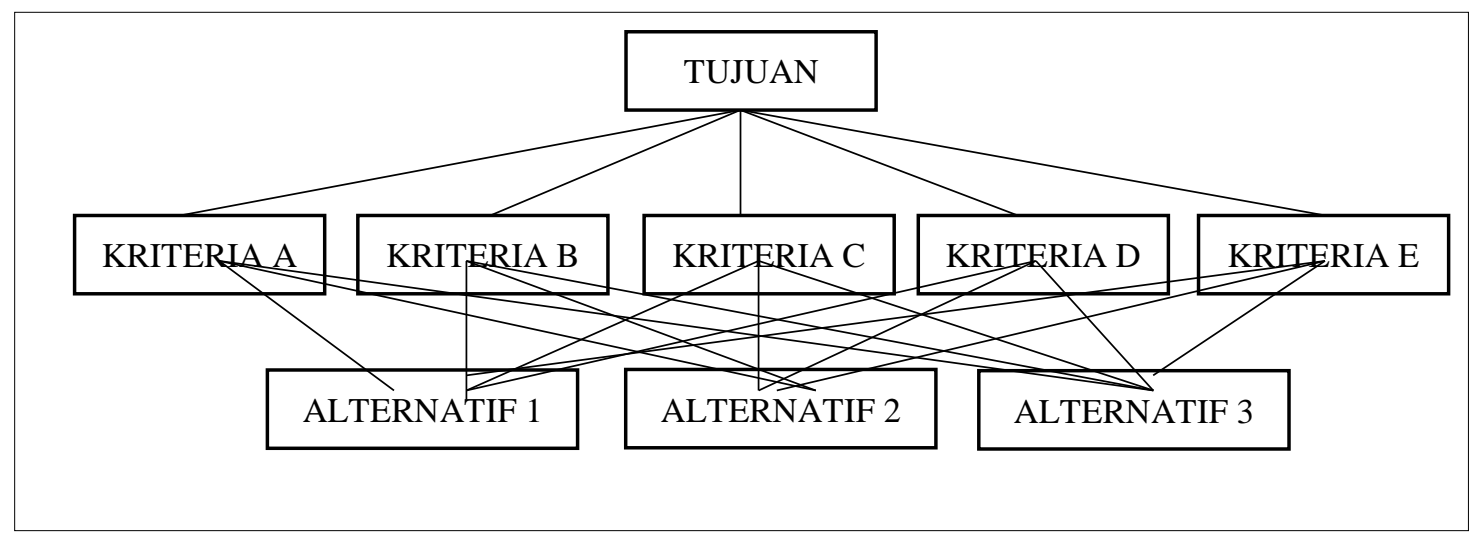

Gambar 1. Hirarki AHP

2. Comparative Judgement, yaitu sebuah proses penilaian kepentingan relatif satu kriteria dengan kriteria lainnya. Penilaian ini berpengaruh pada prioritas kriteria. Hasil penelitian disusun ke dalam matriks perbandingan berpasangan. Hasil perbandingan dari masingmasing elemen kriteria berupa angka 1-9 yang telah ditetapkan oleh Saaty seperti tabel 1 berikut :

Tabel 1. Skala Saaty

\begin{tabular}{cl}
\hline Skala & \multicolumn{1}{c}{ Keterangan } \\
\hline 1 & Kedua elemen atau alternatif sama penting \\
3 & Elemen A sedikit lebih utama dari kriteria B \\
5 & Elemen A lebih utama dari elemen B \\
7 & Elemen A jelas lebih utama dari elemen B \\
9 & Elemen A mutlak lebih utama dari elemen B \\
$2,4,6,8$ & Nilai-nilai antara di antara dua perimbangan yang berdekatan \\
\hline
\end{tabular}

3. Synthesis of Priority yaitu cara dengan menggunakan nilai eigen vector untuk mendapatkan nilai dari bobot relatif bagi unsur pengambil keputusan.

4. Logical Consistency yaitu penilaian kepentingan relatif yang konsisten untuk kriteria yang saling berkaitan.

Adapun langkah yang dilakukan untuk menentukan prioritas proyek menggunakan metode AHP yaitu menggambarkan permasalahan berdasarkan dari kriteria, alternatif dengan struktur pada Gambar 2. Setelah disusun hirarki, langkah selanjutnya menentukan perbandingan berpasangan ke dalam bentuk matriks. Setelah diketahui masing-masing nilai elemen dari matriks hitung nilai prioritas dari setiap kriteria :

1. Menjumlahkan nilai elemen dari setiap kolom matriks

2. Membagi nilai elemen dari setiap kolom dengan jumlah nilai kolom yang sesuai

3. Hitung nilai prioritas kriteria dengan menjumlahkan tiap baris dan hasilnya dibagi dengan banyaknya elemen (elemen=kriteria)

Selanjutnya, setelah mendapatkan nilai prioritas dari masing-masing kriteria, cek nilai konsistensi perbandingan antar kriteria tersebut :

1. Elemen pada kolom matriks dikalikan dengan nilai prioritas yang bersesuaian

2. Hasil dari perkalian kemudian dijumlahkan pada setiap baris

3. Jumlah tiap baris dibagi dengan nilai prioritas yang sesuai

4. Mencari nilai eigen value ( $\lambda \max )$ dengan cara menjumlahkan tiap baris dibagi dengan prioritas yang sesuai (pada langkah c), kemudian dibagi dengan jumlah elemen

5. Menghitung indeks konsistensi (Consistency Index) dengan rumus pada persamaan (1) : 
$\mathrm{CI}=\lambda \max -\mathrm{n} / \mathrm{n} 1$

(1)

Dimana $\mathrm{CI}=$ Consistency Index $; \lambda \max =$ nilai rata-rata dari kriteria; $\mathrm{n}=$ jumlah kriteria

6. Menghitung nilai CR (Consistency Ratio) dnegan rumus pada persamaan (2) :

$\mathrm{CR}=\mathrm{CI} / \mathrm{IR}$

Dimana $C R=$ Consistency Ratio $; C I=$ Consistency Index; $I R=$ Index Ratio

Nilai IR dapat dilihat pada Tabel 2 disesuaikan dengan jumlah elemen atau kriteria

Tabel 2. Index Ratio

\begin{tabular}{cc}
\hline $\mathbf{N}$ & $\mathrm{IR}$ \\
\hline 1 & 0 \\
2 & 0 \\
3 & 5,8 \\
4 & 0,9 \\
5 & 1,12 \\
6 & 1,24 \\
7 & 1,32 \\
8 & 1,41 \\
9 & 1,45 \\
10 & 1,49 \\
\hline
\end{tabular}

\section{HASIL DAN PEMBAHASAN}

Untuk menentukan prioritas proyek dalam penelitian ini terdapat beberapa kriteria dan kategori seperti pada gambar 2 :

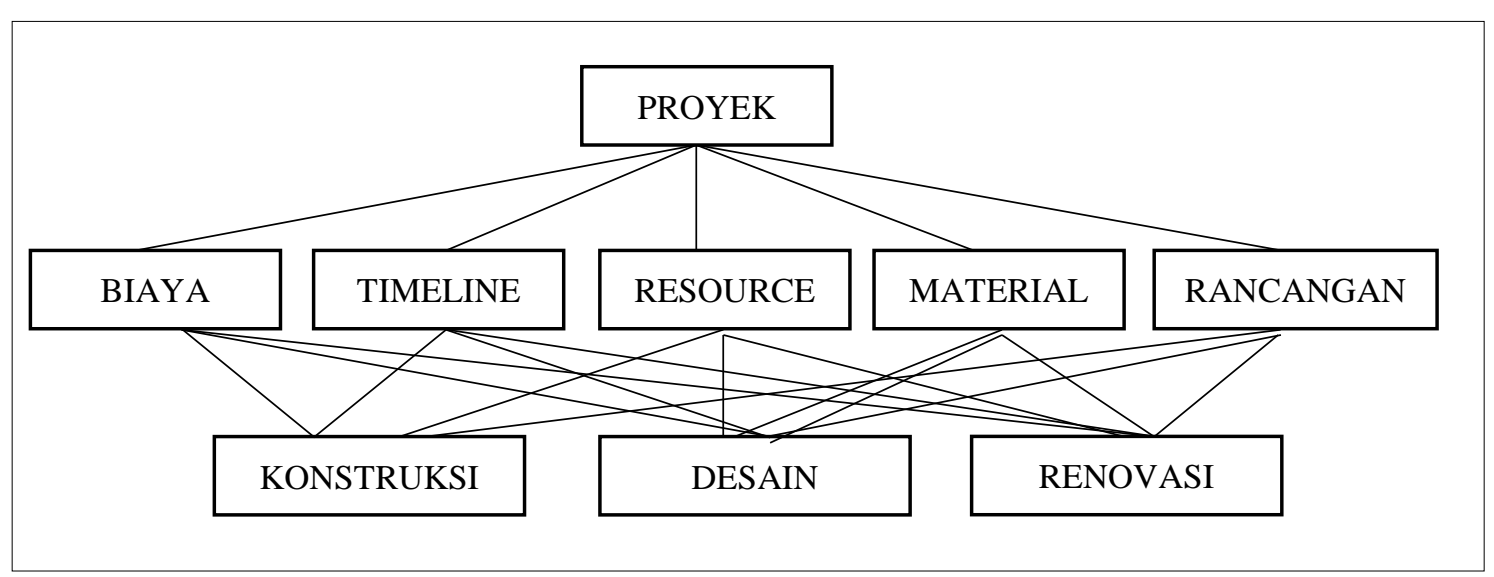

Gambar 2. Hirarki untuk menentukan prioritas proyek

Tabel 3. Matriks Perbandingan Berpasangan Kriteria

\begin{tabular}{lccccc}
\hline Kriteria & Biaya & Timeline & Resource & Material & Rancangan \\
\hline Biaya & 1 & 2 & 1 & 2 & $1 / 2$ \\
Timeline & $1 / 2$ & 1 & 2 & 3 & $1 / 3$ \\
Resource & 1 & $1 / 2$ & 1 & 3 & $1 / 3$ \\
Material & $1 / 2$ & $1 / 3$ & $1 / 3$ & 1 & $1 / 3$ \\
Rancangan & 2 & 3 & 3 & 3 & 1 \\
Jumlah & 5,0 & 6,8 & 7,3 & 12,0 & 2,5 \\
\hline
\end{tabular}


Terdapat 5 kriteria diantaranya biaya, timeline, resource, material dan rancangan. Sedangkan alternatif terdiri dari 3 yaitu konstruksi, desain, rancangan. Untuk menentukan matriks perbandingan berpasangan dilakukan dengan cara membuat perbandingan antara satu kriteria dengan kriteria lainnya. Matriks perbandingan berpasangan dapat dilihat pada tabel 3 .

Untuk nilai dari perbandingan dengan kriteria yang sama bernilai 1 karena keduanya sama penting. Untuk kriteria biaya dibandingkan dengan kriteria timeline bernilai 2 memiliki arti keduanya memiliki nilai yang berimbang. Sebaliknya untuk mengisi nilai kebalikan perbandingan antara kriteria timeline dengan biaya isi dengan nilai $1 / 2$. Untuk hasil nilai perbandingan kriteria timeline dengan kriteria material bernilai 3 yang memiliki arti kriteria timeline sedikit lebih penting dibandingkan dengan kriteria material. Selebihnya jika nilai elemen A dengan nilai elemen B bernilai angka skala 2-9 untuk nilai perbandingan berbalik diisi dengan nilai angka 1/n.

Setelah menentukan nilai perbandingan berpasangan pada masing-masing kriteria, langkah selanjutnya dilakukan penjumlahan nilai-nilai dari setiap kolom matriks dapat dilihat pada Tabel III. Nilai jumlah dari kriteria biaya $=5.0$, kriteria timeline $=6,8$ kriteria resource $=$ 7,3 , kriteria material $=12$, kriteria rancangan $=2,5$

Setelah melakukan penjumlahan dari setiap kolom matriks, dilakukan perhitungan normalisasi dapat dilihat pada Tabel 4.

Tabel 4. Matriks Normalisasi Perbandingan Kriteria

\begin{tabular}{|c|c|c|c|c|c|c|c|c|c|}
\hline 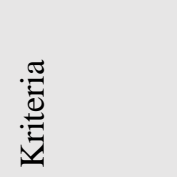 & 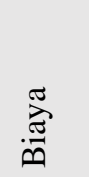 & $\begin{array}{l}\stackrel{\Xi}{\Xi} \\
\stackrel{\Xi}{\Xi}\end{array}$ & 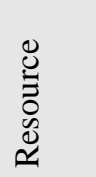 & 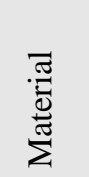 & 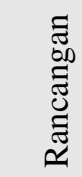 & 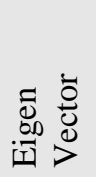 & 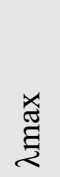 & $\bar{v}$ & త્ \\
\hline Biaya & 0,20 & 0,29 & 0,14 & 0,17 & 0,20 & 0,20 & \multirow{6}{*}{$\begin{array}{l}m \\
m \\
n\end{array}$} & \multirow{6}{*}{$\begin{array}{l}\infty \\
\stackrel{0}{0} \\
0\end{array}$} & \multirow{6}{*}{ : } \\
\hline Timeline & 0,10 & 0,15 & 0,27 & 0,25 & 0,13 & 0,18 & & & \\
\hline Resource & 0,20 & 0,07 & 0,14 & 0,25 & 0,13 & 0,16 & & & \\
\hline Material & 0,10 & 0,05 & 0,05 & 0,08 & 0,13 & 0,08 & & & \\
\hline Rancangan & 0,40 & 0,44 & 0,41 & 0,25 & 0,40 & 0,38 & & & \\
\hline CEK & 1,00 & 1,00 & 1,00 & 1,00 & 1,00 & 1,00 & & & \\
\hline
\end{tabular}

Setiap nilai normalisasi diperoleh dari perhitungan nilai kolom dibagi dengan nilai jumlah kolom kriteria pasangannya. Nilai normalisai pada kolom biaya diperoleh 0,20 didapat dari hasil nilai kolom biaya pada Tabel 3 dibagi dengan nilai jumlah kolom biaya.

Pada kolom Tabel 4 nilai eigen vector diperoleh dari hitungan :

1. Kriteria biaya :

$(0,20+0,29+0,14+0,17+0,20) / 5=0,20$

2. Kriteria timeline :

$(0,10+0,15+0,27+0,25+0,13) / 5=0,18$

3. Kriteria resource :

$(0,20+0,07+0,14+0,25+0,13+0,16) / 5=0,16$

4. Kriteria material :

$(0,10+0,05+0,05+0,08+0,13) / 5=0,08$

5. Kriteria rancangan :

$(0,40+0,44+0,41+0,25+0,40) / 5=0,38$

6. Nilai $\lambda \max :(5 * 0,20)+(6,8 * 0,18)+(7,3 * 0,16)+(12 * 0,08)+(2,5 * 0,38)=5,33$

7. $\mathrm{CI}=\lambda \max -\mathrm{n} / \mathrm{n}-1$

$\mathrm{CI}=5,33-5 / 5-1=0,082$

8. $\mathrm{CR}=\mathrm{CI} / \mathrm{IR}$

$\mathrm{CR}=0,08 / 1,12=0,07$

Dari perhitungan diatas nilai $\mathrm{CR}<0,1$ sehingga nilai rasio konsistensi dapat diterima. 
Perhitungan Matriks Perbandingan Masing-masing Alternatif dan Normalisai Kriteria Terhadap Alternatif.

Tabel 5. Normalisasi Kriteria Terhadap Alternatif

\begin{tabular}{ccccccc}
\hline KRITERIA & \multicolumn{3}{c}{ Alternative } & $\lambda \max$ & CI & CR \\
\cline { 2 - 5 } & Konstruksi & Desain & Renovasi & & & \\
& Eigen & Eigen & Eigen & & & \\
Vector & Vector & Vector & & & \\
Biaya & 0,63 & 0,11 & 0,26 & 2,39 & $-0,31$ & $-0,05$ \\
Timeline & 0,46 & 0,09 & 0,46 & 3 & 0 & 0 \\
Resource & 0,64 & 0,07 & 0,28 & 3,10 & 0,05 & 0,01 \\
Material & 0,65 & 0,22 & 0,14 & 3,70 & 0,35 & 0,06 \\
Rancangan & 0,39 & 0,44 & 0,17 & 3,02 & 0,01 & 0,00 \\
\hline
\end{tabular}

Nilai eigen vector pada tabel 5 diperoleh dari nilai masing-masing eigen vector perhitungan normalisasi kriteria terhadap nilai alternatif. Langkah selanjutnya adalah proses menghitung Overall Composite Weight yang diperoleh dari hasil penjumlahan terhadap perkalian dari setiap nilai Eigen Vector alternatif dengan nilai Eigen Vector kriteria sehingga diperoleh hasil akhir perangkingan seperti tabel 6 .

Tabel 6. Overall CompositeWeight

\begin{tabular}{|c|c|c|c|c|c|c|c|c|c|c|c|}
\hline \multirow[t]{2}{*}{ Summary } & \multicolumn{2}{|c|}{ Biaya } & \multicolumn{2}{|c|}{ Timeline } & \multicolumn{2}{|c|}{ Resource } & \multicolumn{2}{|c|}{ Material } & \multicolumn{2}{|c|}{ Rancangan } & \multirow[b]{2}{*}{ 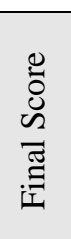 } \\
\hline & 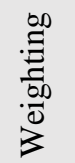 & 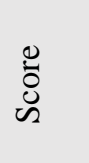 & 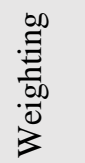 & 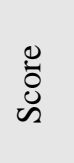 & 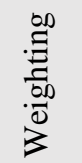 & $\begin{array}{l}0 \\
\tilde{5} \\
\mathscr{U}\end{array}$ & 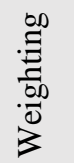 & $\begin{array}{l}0 \\
\stackrel{0}{0} \\
\ddot{n}\end{array}$ & 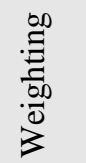 & $\begin{array}{l}0 \\
\text { రू } \\
\tilde{n}\end{array}$ & \\
\hline Konstruksi & 0,20 & 0,633 & 0,18 & 0,46 & 0,16 & 0,64 & 0,08 & 0,65 & 0,38 & 0,39 & 0,51 \\
\hline Desain & 0,20 & 0,11 & 0,18 & 0,09 & 0,16 & 0,07 & 0,08 & 0,22 & 0,38 & 0,44 & 0,24 \\
\hline Renovasi & 0,20 & 0,26 & 0,18 & 0,46 & 0,16 & 0,28 & 0,08 & 0,14 & 0,38 & 0,17 & 0,25 \\
\hline & & & & & & & & & & & 1,00 \\
\hline
\end{tabular}

Untuk nilai Weighting diperoleh dari nilai Eigen Vector masing-masing kriteria, nilai dapat dilihat pada Tabel VI sedangkan untuk nilai Score diperoleh dari nilai Eigen Vector normalisasi setiap alternatif. Hasil dari perhitungan Overall Composite Weight diperoleh nilai perangkingan : Konstruksi $=0,51 ;$ Renovasi $=0,25 ;$ Desain $=0,24$.

\section{KESIMPULAN}

Hasil analisa menggunakan metode AHP untuk menentukan prioritas proyek dapat disimpulkan bahawa hasil perbandingan kriteria peringkat pertama dengan nilai paling tinggi 0,380 untuk kriteria desain, peringkat kedua 0,199 untuk kriteria biaya, peringkat ketiga 0,180 untuk kriteria timeline, peringkat keempat 0,159 untuk kriteria resource dan peringkat terakhir 0,082 untuk kriteria material.Sedangkan untuk hasil perbandingan alternatif berdasarkan hasil dari nilai perbandingan secara keseluruhan yaitu Konstruksi dengan nilai 0,510, alternatif kedua Renovasi dengan nilai 0,254, alternatif ketiga Desain dengan nilai 0,235. 


\section{SARAN}

Dalam penyusunan penelitian metode AHP ini diperlukan ketelitian dalam memasukan nilai perbandingan matriks sesuai dengan masing-masing nilai kriterianya, karena jika tidak teliti maka nilai yang akan didapatkan akan bernilai tidak konsisten. Penelitian ini masih jauh dari sempurna sehingga diharapkan dapat mengkombinasikan metode AHP dengan metode algoritma lain seperti dengan algoritma Fuzzy dan lainnya agar data-data yang tidak tepat dapat ditoleransi sehingga hasil yang diberikan lebih akurat lagi.

\section{DAFTAR PUSTAKA}

[1] S. Putri et al., "Rencana kegiatan proyek yang baik serta pengendalian dalam pelaksanaannya yang efisien dapat menentukan keberhasilan suatu pelaksanaan proyek . Biaya , mutu dan waktu diperhatikan dalam perencanaan dan pengendalian yang dikelola suatu proyek konstruksi ."

[2] S. Sumiyatun and R. Wardoyo, "Kombinasi Metode Anp Dan Topsis Dalam Menentukan Prioritas Media Promosi Perguruan Tinggi (Studi Kasus: Stmik Akakom Yogyakarta)," JIKO (Jurnal Inform. dan Komputer), vol. 1, no. 2, pp. 21-27, 2016.

[3] R. Ardiansyah, M. A. Muslim, and R. N. Hasanah, "Analisis Metode Fuzzy Analytical Network Process untuk Sistem Pengambilan Keputusan Pemeliharaan Jalan,” J. Nas. Tek. Elektro dan Teknol. Inf., vol. 5, no. 2, pp. 122-128, 2016.

[4] A. Prakoso and N. Negoro, "Analisa Strategi Pemasaran Produk Kosmetik Wardah Dengan Pendekan SWOT-AHP (Analytic Hierarchy Process)," J. Sains dan Seni ITS, vol. 6, no. 1, pp. 62-67, 2017.

[5] D. N. Ilham and S. Mulyana, "Sistem Pendukung Keputusan Kelompok Pemilihan Tempat PKL mahasiswa dengan Menggunakan Metode AHP dan Borda," IJCCS (Indonesian J. Comput. Cybern. Syst., vol. 11, no. 1, p. 55, 2017.

[6] Rajamuddin, "Sistem Pendukung Keputusan Penilaian Kinerja Untuk Memilih Dosen Berprestasi Menggunakan Metode AHP," Progress, vol. 7, no. 2, pp. 71-78, 2015.

[7] D. Monita, "Sistem Pendukung Keputusan Penerima Bantuan Langsung Tunai Dengan Menggunakan Metode Analytical Hierarcy Process Diterbitkan Oleh : STMIK Budi Darma Medan Diterbitkan Oleh : STMIK Budi Darma Medan," Pelita Inform. Budi Darma, vol. III, no. April, pp. 29-36, 2013.

[8] M. Moedjiono, N. R. Kurnianda, and A. Kusdaryono, "Decision Support Model for User Submission Approval Energy Partners Candidate Using Profile Matching Method and Analytical Hierarchy Process," Sci. J. Informatics, vol. 3, no. 2, pp. 197-206, 2016.

[9] I. Ranggadara and R. Sahara, "Analytical Hierarchy Process Algorithm Approach for Determining Best Employee (Case Study IT Company in Jakarta)," Int. J. Comput. Sci. Mob. Comput., vol. 6, no. 12, pp. 59-64, 2017.

[10] G. M. Azza and A. Dores, "Sistem Informasi Manajemen Marketing Tools Serta Penerapan Metode Ahp (Analytical Hierarchy Process) Pada Proses Uji Kualitas Barang (Studi Kasus : PT Edi Indonesia)," J. Cendikia, vol. XVI, pp. 107-114, 2018. 